\title{
Effect of seat inclination on intradiscal pressure during simulated driving task, assessed using a biomechanical model
}

\author{
Efecto de la inclinación de la silla en la presión intradiscal durante \\ actividades de manejo simuladas, evaluado con un modelo biomecánico
}

Fernanda Maradei $^{1} \quad$ Leonardo Quintana $^{2} \quad$ Javier Castellanos $^{3 *}$

Recibido 30 de mayo 2014, aceptado 2 de diciembre de 2015

Received: May 30,2014 Accepted: December 2, 2015

\begin{abstract}
This work aimed to develop a mathematical model to evaluate the effect of seat inclination using as input the biomechanical characteristics of the user. The biomechanical model includes weight, posture, flexion of the pelvis and trunk and $5^{\circ}$ and $-5^{\circ}$ seat inclinations. Using actual data collected during an experiment with 26 participants, a validation process was carried out to measure the model's ability to correctly predict load values on the ischial tuberosity. The results show a consistent model with an accuracy of $82 \%$ and a predictive quality of pred $(25)=0.77$. Another outcome of the study is an equation to calculate the intradiscal pressure based on the load at the ischial tuberosity. The biomechanical model and the equations can be used to assess the effects of inclination of the seat and its backrest in chair design processes.
\end{abstract}

Keywords: Biomechanical, driving activities tilt, sitting posture, intradiscal load.

\section{RESUMEN}

Este trabajo se orientó al desarrollo de un modelo matemático para evaluar el efecto de la inclinación de la silla teniendo en cuenta las características biomecánicas del usuario. El modelo incluye el peso corporal, la postura, la flexión de la pelvis y el tronco, y se consideran inclinaciones en el asiento de $5^{\circ}$ y $-5^{\circ}$. A partir de la información recogida durante un experimento con 26 participantes se realizó un proceso de validación para medir la habilidad del modelo para predecir correctamente los valores de la carga en la tuberosidad isquiática. Los resultados muestran que el modelo es consistente puesto que su precisión es de $82 \%$ y la calidad de predicción de pred $(25)=0,77$. Se desarrolló también una ecuación para calcular la presión intradiscal a partir de la carga en la tuberosidad isquiática. El modelo biomecánico y sus ecuaciones pueden ser utilizados para analizar los efectos de la inclinación de la silla y de su espaldar en los procesos de diseño de asientos.

Palabras clave: Biomecánica, inclinación del asiento, postura sedente, carga intradiscal.

\footnotetext{
1 Industrial Design Department. Universidad Industrial de Santander. Bucaramanga, Colombia. E-mail: mafermar@uis.edu.co; fmaradeig@hotmail.com

2 Industrial Engineering Department. Pontificia Universidad Javeriana. Bogotá, Colombia. E-mail: lquin@ javeriana.edu.co

3 Mechanical Engineering Department. Universidad Pontificia Bolivariana. Bucaramanga, Colombia.

E-mail: javier.castellanos@upb.edu.co

Corresponding author
} 


\section{INTRODUCTION}

The seated posture in office work has been extensively studied by different authors [1-5]. The purpose has always been improving postural demands and reducing the risks associated. Although drivers population has been pointed out because its increased risk of developing conditions such as low back pain $[6,7]$, there have not been a great number of studies on the driving seated posture and meanwhile, the prevalence of LBP (low back pain) among this population remains being one of the highest [8-10].

Poor nutrition of intervertebral discs leads to a degenerative process and is strongly associated with back pain $[1,11]$. The kyphosis due to the flexion of the trunk maintains a continuous pressure of the discs resulting in dehydration [12]. This is one of the reasons for low back pain among drivers [13].

A literature review on ergonomics chair requirements for drivers shows that they are largely focused on reducing the discomfort or risks factor for low back pain. Therefore, studies are aimed on defining specifications for lumbar supports [14-16], dimensions and inclination of the seat and backrest [14, 17-19] and cushion features [20-23]; others, focus on the effects of vibration [24-25]. However, it seems that the key to reducing low back pain in seated posture has not been found yet, since the prevalence of the disease remains high.

Actually, the intradiscal pressure determines the biomechanical load on the spine. Particularly, the study of the typological characteristics of the seated posture has been the key to find the less demanding postures [26-27]. However, the invasive nature of these studies result in least population willing to participate in them $(n=1)$ which leads to important limitations in the results due to factors such as body mass index (BMI) that may influence the final load on the spine [28].

Conversely, the review by De Looze [43] shows that the pressure distribution of the ischial tuberosity has been generally used for seats studies as there is a clear association with discomfort scales [15, $27,29]$. Other than being a noninvasive method, it enables the estimation of the intervertebral disc compression based on biomechanical models [30]. The biomechanical models reviewed did not use this measure for its estimates focusing only on trunk flexion regardless of the inclination of the pelvis $[3,23]$ or the curvature of the lumbar spine that affects intradiscal pressure [31]. Other models developed using computer-based systems are limited by the use of specific programs they were created for, restricting the use in the seats design community [32-33].

On the other hand, there is evidence that biomechanically less demanding seated postures are not necessarily comfortable [34-35]. This relationship has been studied in office postures [36], but not in driving tasks, therefore, it was necessary to analyze it in the context of this project. It revealed that seat inclination postures of $5^{\circ}$ and $-5^{\circ}$ angles are perceived as less uncomfortable. According to the literature, available studies suggest that forward seat inclination improves body pressure distribution on the seat and minimizes muscular effort to maintain stability [2-3], conditions which lead to the absorption of vibration. This fact explains why a forward inclination of the seat, which is not too pronounced, is perceived as comfortable.

Accordingly, this research aimed to develop and validate a biomechanical model that includes weight, posture and flexion of the pelvis and trunk to estimate, based on simple formulas, the intradiscal pressure in seat inclinations of $5^{\circ}$ and $-5^{\circ}$. This tool will assess the inclination of the seat according to the biomechanical characteristics of the subject, which will turn into a useful tool for decision-making in the seat design field.

\section{MATERIAL AND METHODS}

\section{Biomechanical Model}

\section{Biomechanical and physiological considerations} Moving from a standing to a seated posture is due to the flexion of the pelvis, which rotates backwards. Flexion of the hip is not folded at a right angle on the femur. Such bending is only about $60^{\circ}$, whereas the angles needed to form $90^{\circ}$ in the seated posture are achieved by lowering kyphosis, that is, moving the spine forward about $30^{\circ}$ [2]. Also, it should be considered that the maximum flexion of the spine is $60^{\circ}$ [37]. 
When the posture is posterior, i.e. supported on the back, studies show that the inclination of the backrest result in a low reading of electromyographic signals because the posterior lumbar spine muscles are relaxed $[2,38]$. Therefore, the model does not consider reactions as a result of muscle forces when leaning on the backrest.

Body weights were taken based on the online software tool PSC from the Universidad Politécnica de Valencia.

To calculate the intradiscal pressure it is considered that the radius ( $\mathrm{r}$ ) of an intervertebral disc for an adult is about $0.02 \mathrm{~m} \mathrm{[3]}$.

When the angle between the trunk and the thigh $(\lambda)$ is less than $120^{\circ}$ a reduction of lumbar kyphosis is generated by creating extra pressure $(\mathrm{P})$ on the intervertebral discs. In this way, it is considered that the intradiscal pressure increases linearly, considering the minimum pressure while being in a standing posture where $\mathrm{P}=0.5$ when trunk flexion equal to zero, i.e. $\beta$ $=0[26]$ and the maximum pressure in sitting posture with maximal trunk flexion, where $\mathrm{P}=0.83 \mathrm{~Pa}$ when $\beta=60^{\circ}$ [26], i.e. the increase in intradiscal pressure is $0.33 \mathrm{~Pa}$. Therefore, when $\lambda<120^{\circ}$ a pressure of $\mathrm{P}_{\text {adicional }}=0.0055 \beta \mathrm{Pa}$ will be added.

Table 1 was used to measure the centers of gravity for each body segment [31]. Table 2 shows the nomenclature used to identify variables and their description.

Table 1. Distance of centers of mass of each body segment.

\begin{tabular}{|l|c|c|}
\hline Force & $\begin{array}{c}\text { Point } \\
\text { reference }\end{array}$ & $\begin{array}{c}\text { Distance in } \\
\text { percentage of length }\end{array}$ \\
\hline $\mathrm{Wg}$ & $\mathrm{R}$ & 43 \\
\hline $\mathrm{Wf}$ & $\mathrm{T}$ & 44 \\
\hline $\mathrm{Wp}$ & $\mathrm{L}$ & 50 \\
\hline $\mathrm{Wcbt}$ & $\mathrm{C}$ & 17 \\
\hline
\end{tabular}

\section{Mechanical system diagram and system of equations}

The Figure 1 shows the biomechanical model. This model includes the body segments that directly influence the intradiscal pressure. All the subsequent force diagrams for each segment were made based on the biomechanical model proposed.
Table 2. List of the nomenclature of each variable and its description.

\begin{tabular}{|c|c|}
\hline Variable & Description \\
\hline$\beta$ & Trunk flexion angle based on the vertical \\
\hline$\alpha$ & Backrest inclination \\
\hline$\phi$ & Pelvis angle \\
\hline$\theta$ & Seat inclination \\
\hline$\delta$ & Knee angle \\
\hline$\lambda$ & Trunk-thigh angle \\
\hline $\mathrm{W}$ & Body weight \\
\hline $\mathrm{Wp}$ & Force exerted by the weight of the pelvis \\
\hline Wf & Force exerted by the weight of the thighs \\
\hline $\mathrm{Wg}$ & $\begin{array}{l}\text { Force exerted by the weight of the legs } \\
\text { and feet }\end{array}$ \\
\hline Wcbt & $\begin{array}{l}\text { Force exerted by the weight of the head, } \\
\text { arms, hands and trunk }\end{array}$ \\
\hline FNE & Reaction force due to support \\
\hline $\mathrm{Lx}$ & Reaction at point $\mathrm{L}$ on the $\mathrm{X}$-axis \\
\hline Ly & Reaction at point $\mathrm{L}$ on the $\mathrm{y}$-axis \\
\hline Ln & Reaction at point $\mathrm{L}$ on the normal axis $n$ \\
\hline $\mathrm{Tx}$ & Reaction at point $\mathrm{T}$ on the $\mathrm{x}$-axis \\
\hline Ty & Reaction at point $\mathrm{T}$ on the $\mathrm{y}$-axis \\
\hline $\mathrm{N}$ & Reaction force due to support \\
\hline $\mathrm{Rx}$ & Reaction at point $\mathrm{R}$ on the $\mathrm{x}$-axis \\
\hline Ry & Reaction at point $\mathrm{R}$ on the $\mathrm{y}$-axis \\
\hline $\mathrm{Px}$ & $\begin{array}{l}\text { Reaction force due to support on the } \\
\mathrm{x} \text {-axis }\end{array}$ \\
\hline Py & $\begin{array}{l}\text { Reaction force due to support on the } \\
y \text {-axis }\end{array}$ \\
\hline $\mathrm{r}$ & Radius of intervertebral disc \\
\hline $\mathrm{P}$ & Intradiscal pressure \\
\hline
\end{tabular}

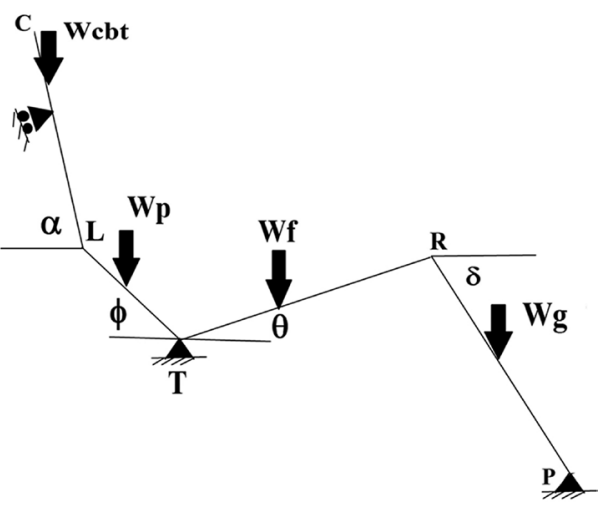

Figure 1. Biomechanical model.

From segment CL (Figure 2):

$$
\sum F y=0=F N E \cos \alpha-W c b t+L x
$$




$$
\begin{gathered}
\sum F x=0=F N E \sin \alpha-L y \\
\sum M_{L}=0=(W c b t \cos \alpha * 0.83 \overline{C L})- \\
(F N E * 0.5 \overline{C L})
\end{gathered}
$$
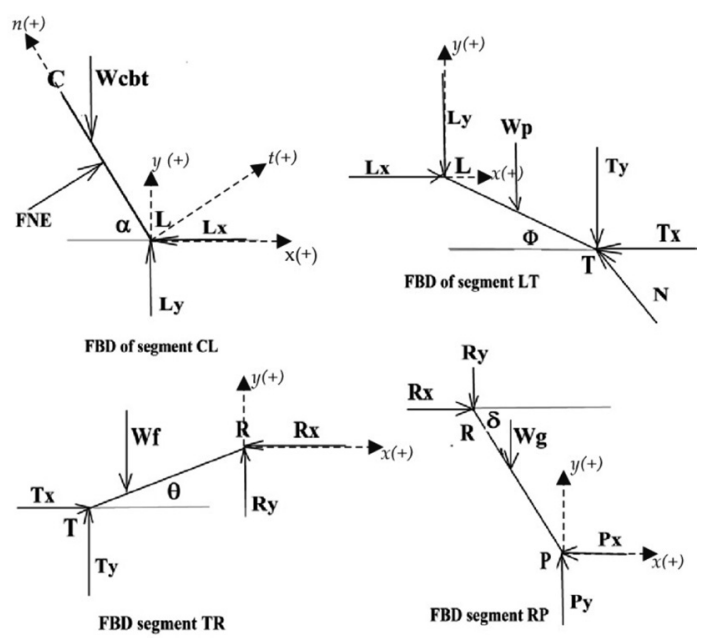

Figure 2. Free Body Diagrams.

Clear FNE from equation (3a)

$$
F N E=1.66 * W c b t \cos \alpha
$$

From segment LT (Figure 2):

$$
\begin{gathered}
\sum F y=0=N y-W p-L y-T y \\
\sum F x=0=L x-T x-N x \\
\sum M_{L}=0=((N x+T x) \overline{L T} * \sin \phi)+ \\
(W p * 0.5 \overline{L T} * \cos \phi)+(T y * \overline{L T} * \cos \phi)- \\
(N y * \overline{L T} * \cos \phi)
\end{gathered}
$$

$$
\begin{gathered}
\sum M_{P}=0=(R x * \overline{R P} * \sin \delta)- \\
(R y * \overline{R P} * \cos \delta)-(W g * 0.57 \overline{R P} * \cos \delta)
\end{gathered}
$$

The reaction in each of the ischial tuberosity is equal to:

$$
N=\sqrt{N x^{2}+N y^{2}}
$$

Intradiscal pressure is equal to (segment CL, Figure 2):

$$
\begin{gathered}
P={ }^{L n} /_{\pi r^{2}}=\left[{ }^{W c b t} \sin \alpha /{ }_{\pi * 0.02^{2}}\right]+ \\
0.0055 \beta \text { if } \lambda<120^{\circ}
\end{gathered}
$$

Bearing in mind that we must validate the biomechanical model, we sought to simplify the equations obtained to used them in a simple way that depends on body weight (W) as shown below. According to the literature, the posture selected was considered ergonomics. It has a seat-back angle of $105^{\circ}\left(\alpha=75^{\circ}\right)$ relative to the horizontal [38], the knee angle of $70^{\circ}(\delta)[39]$, the angle between trunk - thigh $(\lambda)$ always between $121^{\circ}$ and $60^{\circ}$ leading to a pelvic angle $(\phi)$ of $30^{\circ}$. Seat angles $(\theta)$ will be equal to $+5^{\circ}$ and $-5^{\circ}$ (see Table 3 ).

From segment TR (Figure 2):

$$
\begin{gathered}
\sum F y=0=R y+T y-W f \\
\sum F x=0=T x-R x \\
\sum M_{R}=0=(T y * \overline{T R} * \cos \theta)- \\
(W f * 0.56 \overline{T R} * \cos \theta)+(T x * \overline{T R} * \sin \theta)
\end{gathered}
$$

From segment RP (Figure 2):

$$
\sum F y=0=P y-R y-W g
$$

Table 3. Equations for calculation of the pressure on the seat based on body weight.

\begin{tabular}{|c|c|c|}
\hline $\begin{array}{c}\text { Seat } \\
\text { inclination }(\theta)\end{array}$ & $\begin{array}{c}\text { Correction } \\
\text { factor }(\boldsymbol{\mu})\end{array}$ & $\begin{array}{c}\text { Load on } \\
\text { the seat }(\mathbf{N})\end{array}$ \\
\hline$-5^{\circ}$ & 2.95 & equation $(15)$ \\
\hline \multicolumn{2}{|c|}{$N=\mu \sqrt{\left(0.262 W^{2}\right)-(0.273 W)+0.110}$} \\
\hline$+5^{\circ}$ & 2.95 & equation $(16)$ \\
\hline \multicolumn{2}{|c|}{$N=\mu \sqrt{\left(0.309 W^{2}\right)-(0.331 W)+0.110}$} \\
\hline
\end{tabular}

Based on a straight comparison of each of the experimental data with the estimated data in the initial biomechanical model, an adjustment factor that reduces systematic errors in the data set was developed. This factor was included in the final model.

In the same way and keeping the same posture, the equation (14) was simplified to make the calculation of intradiscal pressure easier (Table 4). 
Table 4. Equations for calculation of intradiscal pressure based on body weight.

\begin{tabular}{|c|c|c|}
\hline \multicolumn{3}{|c|}{$\begin{array}{c}\text { Estimated intradiscal pressure based } \\
\text { on the biomechanical model } \\
\boldsymbol{P}=\mathbf{4 2 8 . 5 6} \mathbf{W}-\mathbf{2 7 0 . 8 6 3}\end{array}$} \\
\hline $\begin{array}{c}\text { Seat inclination } \\
(\theta)\end{array}$ & $\begin{array}{c}\text { Extra pressure } \\
(\mathrm{Mpa})\end{array}$ & $\begin{array}{c}\text { Final intradiscal } \\
\text { pressure }(\boldsymbol{P a})\end{array}$ \\
\hline$-5^{\circ}$ & 0.055 & equation $(17)$ \\
\hline \multicolumn{2}{|c|}{$P=[428.56 \mathrm{~W}-270.863]+55000$} \\
\hline$+5^{\circ}$ & 0.11 & equation $(18)$ \\
\hline \multicolumn{3}{|c|}{$P=[428.56 \mathrm{~W}-270.863]+110000$} \\
\hline
\end{tabular}

\section{Biomechanical model validation}

We proceeded to compare the biomechanical model predictions with data from the real world, in order to validate the equations. For this purpose, an experiment that allows measuring the pressure exerted on the seat and the contact area regarding the desired posture was conducted. Based on the mat FSA-ISB it was possible to calculate the load on the ischial tuberosity and proceed to a later comparison with those obtained from the biomechanical model.

\section{Participants}

The actual data collection was conducted with 26 participants, 7 of whom were women and 19 were men. A heterogeneous population was sought to study the equations obtained in different body morphologies. The population has an average weight of $70.11 \mathrm{~kg}$ (DS 14.6), a body mass index (BMI) of 24.87 (DS 4.4) and an age of 34.29 (DS 8.2).

\section{Test description for obtaining the actual data}

After obtaining informed consent from the participants, data collection of age, weight and height was the first step to record the data of the population. Once the equipment that allows to measure the pressure exerted on the seat and backrest was installed on the seat (mat FSAISB), seat inclination was adjusted to $-5^{\circ}$ and $+5^{\circ}$ according to the corresponding treatment. The participant was asked to sit down with a knee angle of $70^{\circ}(\delta)$ and to rest on the backrest. The backrest always had an inclination of $105^{\circ}$ relative to the horizontal. The posture assumed by individuals is the same that was used for the calculation of equations (15) and (16).
Once the adjustments on the seat were set, data collection began for a period of 20 seconds. The first and last 5 seconds of each collection were eliminated, thus each treatment was studied for a period of 10 seconds. At the end of the treatment, the participant was asked to stand up while modifying the inclination of the seat. Once the seat adjustment was set, the participant was asked to assume the seated posture again and the process of collecting data for 20 seconds was repeated.

\section{Statistical analysis of the data}

In this research the coefficient of determination $\left(r^{2}\right)$ was not included in the validation process. Despite being a good indicator of precision it is not a good indicator of accuracy [40]. Therefore, to assess the accuracy of the biomechanical model estimates the techniques recommended by Mendes [41] were used, based on the mean magnitude of relative error $(M M R E)$ and the quality of the prediction, $\operatorname{pred}(l)$ with a $l=25$.

The mean magnitude of the relative error was calculated by using the following equation:

$$
M M R E=1 / n \sum \sum_{i=1}^{n} M R E_{i}
$$

Where MRE is defined as the magnitude of the relative error of each data pair.

The quality of the prediction is calculated as a set of $n$ values where $i$ is the number of them in which $M M R E$ is less than or equal to $l$.

$$
\operatorname{pred}(i)={ }^{i} /_{n}
$$

\section{RESULTS}

\section{Biomechanical model accuracy}

The mean magnitude of the relative error (MMRE) is 0.18 which indicates that on average, the estimated values have $82 \%$ accuracy, which is relatively high and because of that it is considered a good model. The quality of the prediction for a pred (25) is 0.77 which means that $77 \%$ of the estimated data are $75 \%$ accurate. Based on Tedeschi [40] and Mendes [41], the findings suggest that the biomechanical model predicts quite accurately.

The data for load on the seat $(\mathrm{N})$ and intradiscal pressure $(\mathrm{P})$ were estimated according to the biomechanical model already validated. It was found 
that there is a strong correlation $(\mathrm{r}=0.97)$ between them. The trend line that best fits the scatter plot, revealed a possible equation $(\mathrm{P}=0.0003 \mathrm{~N}+0.067)$ to estimate the intradiscal pressure based on data load on the ischial tuberosity (see Figure 3 ).

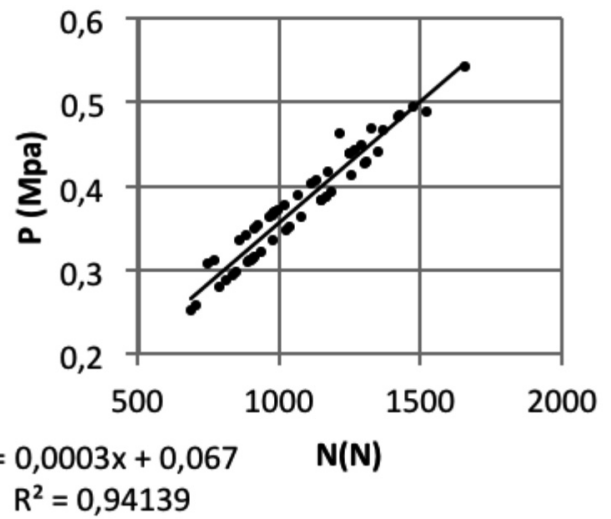

Figure 3. Scatter plot of intradiscal pressure vs. load on the seat.

Biomechanical load depending on seat inclination To determine whether the seat inclination angle affects intradiscal pressure the analysis of variance of the data (ANOVA) found significant differences between groups $(p=0.00)$. Table 5 shows that the forward inclination of the seat (negative angles) promotes the reduction of intradiscal pressure. The mean, minimum and maximum values with an inclination $\theta=-5^{\circ}$ are lower compared to $\theta=+5^{\circ}$.

It was also found that the weight has a significant effect on intradiscal pressure $(\underline{p}=0.003)$. Therefore, if values are compared by gender, men have higher intradiscal loads $(\mu=0.4 \mathrm{Mpa})$ than women $(\mu=$ $0.307 \mathrm{Mpa}$ ) because they are heavier which has nothing to do with the seat inclination.

\section{DISCUSSION}

Biomechanical models are considered an excellent tool for the analysis of internal and external loads on the body structure. As a result, this research aimed to obtain a simple mathematical equation that allows the estimation of load on ischial tuberosity to obtain intradiscal pressure, considering factors such as weight, posture and flexion of the pelvis and trunk. Likewise, the literature has shown that forward inclination of the seat affects intradiscal pressure [3, 32]. Based on literature and prior experimentation, this research uses a seat inclination of $+5^{\circ}$ and $-5^{\circ}$.

Table 5. Description of intradiscal pressure variable depending on the inclination of the seat.

\begin{tabular}{|c|c|c|c|c|}
\hline \multicolumn{5}{|c|}{ Intradiscal pressure * Seat inclination } \\
\hline \multicolumn{5}{|c|}{ Pressure P (MPa) } \\
\hline Seat inclination & $\mathbf{N}$ & Min & Mean & Max \\
\hline$\theta=-5^{\circ}$ & 26 & 0.25 & 0.35 & 0.48 \\
\hline$\theta=+5^{\circ}$ & 26 & 0.30 & 0.40 & 0.54 \\
\hline
\end{tabular}

Although this model is restricted only to the sagittal plane, it has a fairly high level of accuracy that could be improved in future researches considering variables such as torsion or lateral deviation. However, the accuracy of $82 \%$ is considered excellent for predictive models like this one [40-41].

The mathematical equation was obtained from the ergonomics postures of drivers suggested by different authors [38-39], simplifying it in terms of body weight. The weight is one of the most important factors of intradiscal pressure. It can be analyzed in the equations proposed as well as in the analysis of variance of this research. According to Reed [42], anthropometry has no influence on intradiscal pressure as it doesn't determine trunk flexion, but rather the posture assumed in the seat regardless of the size or gender of the person. Likewise, analysis of the equations obtained through this research shows that anthropometry does not affect intradiscal pressure.

In consequence, the biomechanical model proposed allows to analyze the effect of the inclination of the seat on the spine and estimate the intradiscal pressure without performing invasive experiments, as only data from pressure and contact area on the seat is needed.

Regarding the effects of seat inclination on intradiscal pressure, the model works according to the findings of other authors on office tasks [2-3]. Statistically, some differences were found and it was also observed that negative angles (forward seat) cause less demand on the spine. Although this aspect has never been studied in driving activities, this biomechanical model confirms that these findings can also be applied to the postures assumed when 
driving a vehicle. However, the analysis of equations suggests that while the load on the spine is reduced, due to a forward tilt of the seat, the load on the knees joints is increased. This is probably due to the need of holding the body weight as a result of the gliding. Rasmussen's studies [32] show that the coefficient of friction on the seat is one of the factors that affects intradiscal load and suggest that forward inclination must not exceed $10^{\circ}$.

Finally, the estimation values of intradiscal pressure obtained from the biomechanical model are consistent with those obtained from in vivo experiments by other authors [26-27]. It is important to note that equations (17) and (18) were obtained from a model already validated and the level of accuracy of the estimates of intradiscal pressure was not assessed for actual data, thus it is recommended that future researches perform such validations to enhance the equations proposed here.

\section{CONCLUSIONS}

This biomechanical model shows that it is possible to improve the quality of the seated posture in driving activities. The demands on the spine can be decreased to generate intradiscal load variations by changing the seat inclination, which improves the nutrition of intervertebral discs. Therefore, it is necessary to design experiments in order to test these hypotheses for relieving lumbar pain during driving activities. It should be considered that as the aesthetic considerations in chairs are important design requirements, so are the ergonomics considerations, which would improve the perception of comfort by reducing the biomechanical demands on the spine.

Finally, this paper provides a basic tool based on mathematical equations which can be used to analyze the effects of seat inclination and intradiscal pressure resulting from such modifications.

\section{REFERENCES}

[1] D.B. Chaffin, G.B. Andersson and B.J. Martin, Occupational Biomechanics. New York: J. Wiley \& Sons. 2006.

[2] M.R. Jouvencel, Ergonomía Básica. Aplicada a la medicina del trabajo. Madrid, España: Ediciones Diaz Santos. 1994.
[3] C. Lelong, J.G. Drevet, R. Chevallier and $\mathrm{X}$. Phelip. "Biomécanique rachidienne et station assise". Revue du Rhumatisme. Vol. 55, pp. 375-380. 1988.

[4] M.G.M. Thariq, H.P. Munasinghe and J.D. Abeysekara. "Designing chairs with mounted desktop for university students: Ergonomics and comfort". International Journal of Industrial Ergonomics. Vol. 40, pp. 8-18. 2010.

[5] S.M. McGill, N.S. Kavcic and E. Harvey. "Sitting on a chair or an exercise ball: Various perspectives to guide decision making". Clinical biomechanics (Bristol, Avon). Vol. 21, pp. 353-360. 2006.

[6] M. Massaccesi, A. Pagnotta, A. Soccetti, M. Masali, C. Masiero and F. Greco. "Investigation of work-related disorders in truck drivers using RULA method". Applied Ergonomics. Vol. 34, pp. 303-307. 2003.

[7] B.E. Polo, O. Nieto, A. Camacho, J.H. Mejía, M.C. Rueda, N.P. Martinez y M.E. Torres. "Guía de Atención Integrada Basada en la Evidencia para Dolor Lumbar Inespecífico y Enfermedad Discal Relacionado con Manipulación Manual de Cargas y otros Factores de Riesgo en el Lugar de Trabajo (GATI-DLI-ED)". Vol. 1, M. d. 1. P. Social, Ed., ed. Bogotá, p. 135. 2006.

[8] M. Miyamoto, S. Konno, Y. Gembun, X. Liu, K. Minami and H. Ito. "Epidemiological study of low back pain and occupational risk factors among taxi drivers". Industrial Health. Vol. 46, pp. 112-117. 2008.

[9] M. Miyamoto, Y. Shirai, Y. Nakayama, Y. Gembun and K. Kaneda. "An Epiodemiologic Study of Occupational Low Back Pain in Truck Drivers". Journal of Nippon Medical School. Vol. 67, pp. 186-190. 2000.

[10] A.M. Lis, K.M. Black, H. Korn and M. Nordin. "Association between sitting and occupational LBP”. European Spine Journal. Vol. 16, pp. 283-298. 2007.

[11] S.B. Kim Kh Fau - Choe, A.J. Choe Sb Fau - Haig, B.J. Haig Aj Fau - Martin and B.J. Martin. "Adaptation of torso movement strategies in persons with spinal cord injury or low". Spine (Phila Pa 1976). Vol. 35, pp. 1753-9. 2010.

[12] K. Johannaber and F.A. Fathallah. "Spinal disc hydration status during simulated stooped posture". Work: A Journal of Prevention, 
Assessment and Rehabilitation. Vol. 41, pp. 2384-2386. 2012.

[13] D.D. Harrison, S.O. Harrison, A.C. Croft, D.E. Harrison and S.J. Troyanovich. "Sitting biomechanics Part I: Review of the Literature". Journal of manipulative and physiological therapeutics. Vol. 22, pp. 594-609. 1999.

[14] M. Kolich. "Automobile seat comfort: occupant preferences vs. anthropometric accommodation". Applied Ergonomics. Vol. 34, pp. 177-184. 2003.

[15] S. Na, S. Lim, H. S. Choi and M.K. Chung. "Evaluation of driver's discomfort and postural change using dynamic body pressure distribution". International Journal of Industrial Ergonomics. Vol. 35, pp. 10851096. 2005.

[16] M. Reed and L. Schneider. "Design criteria for automobile seatbacks based on preferred driver postures". University of Michigan, Transportation Research Institute. 1995.

[17] M.P. Reed, L.W. Schneider and L.L. Ricci. "Survey of Auto Seat Design Recommendationsfor Improved Comfort". University of Michigan Transportation Research Institute, Michigan, USA. 1994.

[18] H. Fazlollahtabar. "A subjective framework for seat comfort based on a heuristic multi criteria decision making technique and anthropometry". Applied Ergonomics. Vol. 42, pp. 16-28. 2010.

[19] D. Ng, T. Cassar and C. M. Gross. "Evaluation of an intelligent seat system". Applied Ergonomics. Vol. 26, pp. 109-116. 1995.

[20] H. Udo, T. Tajima, S. Uda, F. Yoshinaga, E. Ishihara, Y. Yamamoto, N. Hiura, A. Kataoka, K. Nakai and H. Umino. "Low back load in two car driver seats". International Journal of Industrial Ergonomics. Vol. 20, Issue 3, pp. 215-222. 1997.

[21] G. Kyung, M.A. Nussbaum and K. Babski-Reeves. "Driver sitting comfort and discomfort (part I): Use of subjective ratings in discriminating car seats and correspondence among ratings". International Journal of Industrial Ergonomics. Vol. 38, pp. 516-525. 2008.

[22] B. Hinz, S. Rützel, R. Blüthner, G. Menzel, H.P. Wölfel and H. Seidel. "Apparent mass of seated man - First determination with a soft seat and dynamic seat pressure distributions". Journal of Sound and Vibration. Vol. 298, pp. 704-724. 2006.

[23] C.R. Mehta and V.K. Tewari. "Biomechanical model to predict loads on lumbar vertebra of a tractor operator". International Journal of Industrial Ergonomics. Vol. 47, pp. 104116. 2015.

[24] W. Qassem. "Model prediction of vibration effects on human subject seated on various cushions". Medical engineering \& physics. Vol. 18, pp. 350-358. 1996.

[25] G.J. Stein, P. Mucka, R. Chmurny, B. Hinz and R. Bluthner. "Measurement and modelling of $\mathrm{x}$-direction apparent mass of the seated human body-cushioned seat system". in J Biomech. Vol. 40, pp. 1493-1503. United States. 2007.

[26] H.J. Wilke, P. Neef, M. Caimi, T. Hoogland and L. E. Claes. "New In Vivo Measurements of Pressures in the Intervertebral Disc in Daily Life". Spine. Vol. 24. 1999.

[27] R. Zenk, M. Franz, H. Bubb and P. Vink. "Technical note: Spine loading in automotive seating". Applied Ergonomics. Vol. 43, pp. 290-295. 2012.

[28] T. Mitchell, P.B. O'Sullivan, A.F. Burnett, L. Straker and A. Smith. "Regional differences in lumbar spinal posture and the influence of low back pain". Bmc Musculoskeletal Disorders. Vol. 9, p. 152. 2008.

[29] G. Andreoni, G.C. Santambrogio, M. Rabuffetti and A. Pedotti. "Method for the analysis of posture and interface pressure of car drivers". Applied Ergonomics. Vol. 33, pp. 511-522. 2002.

[30] C. García, R. Moraga, A. Page, L. Torosa and V. Verde. "Guía de recomendaciones para el diseño de mobiliario ergonómico". Instituto de Biomecánica de Valencia. España. 1992.

[31] R.H.M. Goossens and C.J. Snijders. "Design criteria for the reduction of shear forces in beds and seats". Journal of Biomechanics. Vol. 28, pp. 225-230. 1995.

[32] J. Rasmussen, S. Tørholm and M. de Zee. "Computational analysis of the influence of seat pan inclination and friction on muscle activity and spinal joint forces". International Journal of Industrial Ergonomics. Vol. 39, pp. 52-57. 2009.

[33] M. Grujicic, B. Pandurangan, X. Xie, A.K. Gramopadhye, D. Wagner and M. 
Ozen. "Musculoskeletal computational analysis of the influence of car-seat design/ adjustments on long-distance driving fatigue". International Journal of Industrial Ergonomics. Vol. 40, pp. 345-355. 2010.

[34] S.M. Carcone and P.J. Keir. "Effects of backrest design on biomechanics and comfort during seated work". Applied Ergonomics. Vol. 38, pp. 755-764. 2007.

[35] S. Haynes and K. Williams. "Impact of seating posture on user comfort and typing performance for people with chronic low back pain". International Journal of Industrial Ergonomics. Vol. 38, pp. 35-46. 2008.

[36] C. Poncet. "Contraintes, Confort et appuis extra-rachidiens". Master, Mouvement performance santé ingénierie. Universite Joseph Fourier-Grenoble I. 2011.

[37] R.C. Miralles. "Biomecánica de la columna". Revista sociedad española del dolor. Vol. 8, pp. 2-8. 2001.

[38] D.D. Harrison, S.O. Harrison, A.C. Croft, D.E. Harrison and S. J. Troyanovich. "Sitting biomechanics, part II: optimal car driver's seat and optimal driver's spinal model". Journal Of Manipulative And Physiological Therapeutics. Vol. 23, pp. 37-47. 2000.

[39] A.R. Tilley. "The measure of man and women". John Wiley \& sons, Inc. New York, USA. 2002.

[40] L.O. Tedeschi. "Assessment of the adequacy of mathematical models". Agricultural Systems. Vol. 89, pp. 225-247. 2006.

[41] E. Mendes, I. Watson, C. Triggs, N. Mosley and S. Counsell. "A comparison of development effort estimation techniques for web hypermedia applications". Presented at the Eight IEEE Symposium of Software Metrics (Metrics'02). 2002.

[42] M. Reed, M. Manary, C.A.C. Flannagan and L.W. Schneider. "The effects of vehicle interior geometry and anthropometric variables on automobile driving posture". Human Factors. Vol. 42. 2000.

[43] M.P. De Looze, L.F.M. KIuijt-Evers and J. Van dieën. "Sitting comfort and discomfort and the relationships with objective measures". Ergonomics. Vol. 46, pp. 985-997. 2003. 